\title{
A cross-sectional study of quality of life in a cohort of enteral ostomy patients presenting to a tertiary care hospital in a developing country in South Asia
}

\author{
Umesh Jayarajah and Dharmabandhu N. Samarasekera ${ }^{*}$
}

\begin{abstract}
Background: Enteral ostomy creation affects the quality of life $(\mathrm{QOL})$ of stoma patients significantly. Studying the $\mathrm{QOL}$ and its determinants is important as it may help in the early identification of those with poor QOL leading to appropriate intervention. This study was aimed to assess the possible contributory factors of QOL of stoma patients.

Methods: A cross sectional study was conducted among 43 ostomy patients who presented for follow up at a surgical clinic of a tertiary care hospital in Sri Lanka over a period of 1 year. Relevant demographic and ostomy related data were collected using an interviewer administered questionnaire. Stoma quality of life scale (Stoma-QOL) and stoma care self-efficacy scale (SCSE) which are validated questionnaires were used to assess QOL and self-efficacy in managing stoma respectively. Associations were established using independent samples $t$ test and Spearman's correlation.

Results: The median age of the study participants was 47.5 years (range 18-83). The median follow up duration was 38 months (range 6-183). The mean overall QOL score was $53.07 \pm$ SD 12.68. Approximately $70 \%$ of the study participants scored less than 60 . Higher QOL was associated with female sex, colostomies, comfortable income and satisfactory sexual activity. Significantly lower overall QOL was found in those who reported a significant change in the style of dressing $(p<0.05)$, those who felt depressed $(p<0.05)$, and those who had thoughts of self-harm soon after surgery $(p<0.05)$. There was a significant positive correlation between $\mathrm{QOL}$ and self-efficacy $(p<0.01)$. Those who took longer time to learn to take care of the stoma had lower $\mathrm{QOL}(\mathrm{p}<0.05)$.

Conclusions: The overall QOL score was considerably low in our study. The QOL was significantly associated with self-efficacy which indicates the importance of patient education and training during follow up visits to maintain a higher QOL. Furthermore integrating with other non-surgical specialities to address multi-dimensional problems including psychosocial and sexual aspects may be helpful to achieve a better QOL.
\end{abstract}

Keywords: Quality of life, Self-efficacy, Enteral ostomy

\section{Background}

Intestinal ostomy is a surgical procedure that is done to treat several benign and malignant intestinal conditions. Colorectal malignancies, inflammatory bowel disease, polyposis syndromes and trauma are few conditions in which stomas are used. The two most leading causes are

${ }^{*}$ Correspondence: samarasekera58@yahoo.co.uk Department of Surgery, Faculty of Medicine, University of Colombo, P.O. Box 271, Kynsey Road, Colombo 8, Western Province, Sri Lanka colorectal malignancies and inflammatory bowel disease [1]. Furthermore the incidence of colorectal malignancies are on the rise worldwide which is also now seen among the Asian population. The significant increase in morbidity and mortality has made colorectal cancer a major public health concern. Increase in the incidence of colorectal malignancies has significantly contributed to the increase in ostomy creation [2].

In addition, creation of an ostomy has a significant impact on quality of life (QOL) which can present as 
physical, psychological or social disability. Restriction of physical activities, dietary restrictions and sexual difficulties are some of the physical factors which influence the QOL. The patients also face significant change in the perception of body image, general lifestyle and relationship with families and friends [3, 4].

One of the main aims of treating ostomy patients is to improve the QOL and currently significant emphasis is given to this aspect [5]. However studies on QOL among stoma patients in the South Asian region are very scarce and sometimes not measured using validated instruments. Studying the QOL and its determinants is important in the management of ostomy patients as it may help in the early identification of those with poor QOL leading to appropriate intervention.

\section{Methods}

\section{Selection of participants}

All patients who presented for follow up at a surgical clinic of a tertiary care hospital in Sri Lanka over a period of 1 year were enlisted. All those who were above 18 years, who were living with an enteral ostomy and having a willingness to participate were recruited. Those with other physical or psychological morbidities that could interfere with self-care were excluded from this study. Finally 43 patients were selected to participate in this study.

\section{Study design and data collection}

A descriptive cross sectional study was carried out. The study was conducted at the National Hospital of Sri Lanka, Colombo. The data were collected during clinic visits. Details on demographic characteristics, details of the disease and surgical details were gathered. Validated questionnaires were used to collect data.

Demographic characteristics analysed in the study included, age, sex, marital status, ethnicity, educational level, body mass index, and social and psychological support. Details of occupation, sexual activity, psychological aspects and change in food and clothing habits were also collected. The clinical records were used to gather data on related details on ostomy, disease and the treatment which included type of surgery and complications of ostomy.

Written informed consent for participation in the study was obtained from all the participants.

\section{Study instruments}

The quality of life was measured using Stoma-QOL scale [5]. This consisted of 20 items that covered several areas which were concerns due to stoma, sleep, sexual activity, relationship with family and close friends and social interactions with others other than family and close friends.
Participants responded to 20 items on a 4-point Likert scale with numbers referring to $1=$ never, $2=$ occasionally, 3 = frequently, or $4=$ always. The final value was converted to a continuous scale ranging from 0 to 100 . These items were found to define a unidimensional variable according to Rasch specifications (Infit MNSQ < 1.3). Internal consistency reliability was highly reliable as Cronbach's alpha was 0.92 . Spearman's correlation coefficients of scores across times of administration was $>0.88$ ( $\mathrm{p}<0.01)$, indicating a high test-retest reliability. Results of Rasch specifications as well as classical analysis indicate the suitability of the instrument for clinical research [5].

The level of self-efficacy on caring for stoma was measured using stoma care self-efficacy scale (SCSE) [6]. This consisted of 13 items on self-efficacy of managing a stoma. It is designed to assess a general sense of perceived self-efficacy with the aim to assess the coping with day to day difficulties of managing a stoma. The Cronbach's alpha was 0.94 indicating a highly reliable internal consistency. Patients responded to a 5 point Likert scale numbered as $1=$ not being confident at all, $2=$ slightly confident, $3=$ fairly confident, $4=$ highly confident and $5=$ extremely confident. High scores indicate higher perception of self-efficacy. The total score is calculated to 100 whereas less than $50=$ low self-efficacy and more than $50=$ high self-efficacy. A group of experts specialized in General Surgery, Medical-surgical and psychiatric nursing ascertained the content validity. Contents of the tools were tested regarding to the knowledge accuracy, relevance and competence [6].

The questionnaires which were originally in English were translated to local languages and were administered as an interviewer administered questionnaire to minimize discrepancies. The male patients were interviewed by a male investigator and the female patients by a female investigator to collect data on personal information such as sexual function.

\section{Data analysis}

Data were analysed using SPSS 17.0 statistical software (SPSS Inc., USA). Continuous variables were expressed using means \pm standard deviations. For inferential analysis, Spearman's correlations were used to analyse the relationship between continuous demographic variables, self-care, SQOL scores. For independent samples, a $t$ test was used to analyse the relationship between continuous variables and SQOL scores. Statistical testing was performed at the 0.05 significance level.

\section{Results}

\section{Demographic factors}

The median age of the study participants was 47.5 years (range 18-83). The median follow up duration was 
38 months (range 6-183). The majority of the participants were males $(69.5 \%)$, and ethnicity were Sinhalese (62.8\%), Tamil (20.9\%) and Muslim (16.3\%). Of the participants $62.8 \%$ were unemployed with $67.4 \%$ living married (Table 1).

\section{Characteristics of ostomy}

The majority of the patients had a colostomy $(\mathrm{n}=32$, $74.4 \%)$ and the commonest indications were carcinoma of the lower rectum and anus $(\mathrm{n}=16,37.2 \%)$ followed by inflammatory bowel disease $(n=9,20.9 \%)$. Commonest surgery performed was a defunctioning colostomy $(\mathrm{n}=19,44.2 \%)$ followed by abdomino-perineal resection $(\mathrm{n}=8,18.6 \%)$. Other common surgeries were anterior resection, Hartmann's procedure and ileal pouch anal anastomosis.

\section{Complications of ostomy}

The majority of the participants experienced complication of stoma at some point $(\mathrm{n}=22,51.2 \%)$. Of the participants $32.5 \%(\mathrm{n}=14)$ experienced one complication and $18.6 \%(\mathrm{n}=8)$ experienced 2 or more complications. The common complications experienced were skin excoriation $(\mathrm{n}=10,23.3 \%)$, parastomal hernia $(\mathrm{n}=8,18.6 \%)$ and prolapse $(\mathrm{n}=8,18.6 \%)$.

\section{Table 1 Demographic characteristics}

\begin{tabular}{lll}
\hline & Number \\
\hline Sex & 30 & \\
Male & 13 & $(30.5 \%)$ \\
Female & & \\
Ethnicity & 27 & $(62.8 \%)$ \\
Sinhala & 9 & $(20.9 \%)$ \\
Tamil & 7 & $(16.3 \%)$ \\
Muslim & & \\
Employment status & 16 & $(37.2 \%)$ \\
Yes & 27 & $(62.8 \%)$ \\
No & & \\
Income & 7 & $(16.3 \%)$ \\
Comfortable income & 22 & $(51.2 \%)$ \\
Enough to meet important needs & 14 & $(32.6 \%)$ \\
Not enough to meet important needs & & \\
Marital status & 10 & $(23.3 \%)$ \\
Unmarried & 29 & $(67.4 \%)$ \\
Married & 3 & $(7.0 \%)$ \\
Widowed & 1 & $(2.3 \%)$ \\
Separated & & \\
Education level & 19 & $(44.18 \%)$ \\
Below grade 11 & 24 & $(55.82 \%)$ \\
Grade 11 and above & &
\end{tabular}

\section{Quality of life (QOL) following ostomy}

The mean overall QOL score was $53.07 \pm$ SD 12.68 (range 18-82) (Table 2). The associations were determined between possible determinant factors and QOL scores considering both overall score and its components separately. The overall score was out of 100 . The components were scored by determining the mean (minimum possible score 1 and maximum 4). Approximately $70 \%$ of the study participants scored less than 60 . The scores on concerns about stoma and sleep were comparatively poorer. The highest correlation with the overall QOL score was seen with social sub-scale $\left(r_{s}=0.906\right)$ followed by sleep $\left(r_{s}=0.851\right)$ and concerns due to ostomy $\left(r_{s}=0.838\right)$. In our cohort of patients, the sexual/body image scores $\left(r_{s}=0.715\right)$ had the lowest impact on the overall quality of life. $\left(\mathrm{r}_{\mathrm{s}}=\right.$ Spearman's correlation co-efficient).

Of the demographic factors, there was higher QOL in female patients which was not statistically significant $(\mathrm{p}=0.51)$. There was no association between age, body mass index, ethnicity, and marital status with QOL. Those who had a "comfortable" income and those who are employed had a higher overall QOL which was not statistically significant. However, those who had a "comfortable" income had a significantly higher scores measuring family and social relationships (Table 3 ).

Those who were having a loop ostomy had a higher score. Furthermore, there was higher QOL in permanent ostomies compared to temporary ones. Defunctioning ostomies had a higher QOL compared to other types of surgery. However, the difference seen was not statistically significant (Table 4). Patients who underwent rectal surgery and ostomy creation had lower rate of sexual satisfaction $(\mathrm{p}=0.414)$, higher rate of abstinence following ostomy $(\mathrm{p}=0.129)$ and higher rate of impotence $(\mathrm{p}=0.019)$ which was statistically significant, compared to those who had ostomy creation without rectal surgery. There was no significant difference in the overall quality of life in those who underwent rectal surgery. However, the sexual/body image scores were slightly lower in the rectal surgery group, although it was statistically not significant $(\mathrm{p}=0.0 .689)$.

Of the participants who were sexually active prior to surgery $(n=27)$, only $33 \%(n=9)$ resumed sexual

Table 2 Overall and specific QOL scores

\begin{tabular}{lrc}
\hline Scores & Mean & Standard deviation \\
\hline Overall QOL out of 100 & 53.07 & 12.68 \\
Concerns due to stoma & 2.24 & 0.80 \\
Sleep & 2.54 & 0.83 \\
Social and family relationships & 2.74 & 0.92 \\
Sexuality and body image & 2.71 & 0.83 \\
\hline
\end{tabular}


Table 3 Association between QOL and demographic parameters

\begin{tabular}{|c|c|c|c|c|}
\hline & $\mathrm{N}$ & Mean & Standard deviation & p value \\
\hline \multicolumn{5}{|l|}{ Overall QOL with sex } \\
\hline Male & 30 & 51.1890 & 12.79 & \multirow[t]{2}{*}{0.51} \\
\hline Female & 13 & 57.4254 & 11.75 & \\
\hline \multicolumn{5}{|l|}{ Overall QOL with age } \\
\hline Age $<60$ & 31 & 52.5361 & 13.37 & \multirow[t]{2}{*}{0.660} \\
\hline Age $>60$ & 12 & 54.4650 & 11.12 & \\
\hline \multicolumn{5}{|c|}{ Overall QOL with ethnicity } \\
\hline Sinhala & 27 & 53.72 & 11.82 & \multirow[t]{3}{*}{0.892} \\
\hline Tamil & 9 & 51.37 & 16.63 & \\
\hline Muslim & 7 & 52.72 & 12.00 & \\
\hline \multicolumn{5}{|c|}{ Overall QOL with employment status } \\
\hline Employed & 16 & 54.0694 & 11.61 & \multirow[t]{2}{*}{0.69} \\
\hline Unemployed & 27 & 52.4848 & 13.45 & \\
\hline \multicolumn{5}{|c|}{ Overall QOL with income } \\
\hline Comfortable income & 7 & 57.2757 & 6.54 & \multirow[t]{2}{*}{0.46} \\
\hline Other & 33 & 53.3782 & 13.42 & \\
\hline \multicolumn{5}{|c|}{ Family and social relationships scores with income } \\
\hline Comfortable income & 7 & 3.3810 & 0.4879 & \multirow[t]{2}{*}{0.027} \\
\hline Other & 33 & 2.7677 & 1.0257 & \\
\hline \multicolumn{5}{|c|}{ Overall QOL with marital status } \\
\hline Married & 29 & 52.7945 & 13.60 & \multirow[t]{2}{*}{0.41} \\
\hline Others & 14 & 53.6543 & 10.97 & \\
\hline \multicolumn{5}{|c|}{ Overall QOL with education } \\
\hline Less than $\mathrm{O} / \mathrm{L}$ & 33 & 53.12 & 13.60 & \multirow[t]{2}{*}{0.96} \\
\hline O/L or above & 10 & 52.90 & 9.58 & \\
\hline \multicolumn{5}{|l|}{ Overall QOL with BMI } \\
\hline High BMI & 25 & 52.2516 & 11.76 & \multirow[t]{2}{*}{0.53} \\
\hline Low or normal BMI & 17 & 54.7576 & 14.37 & \\
\hline
\end{tabular}

$O / L$ ordinary level examinations

activity following surgery. Only 8 patients were satisfied with their sexual activity. The higher scores were noted in all components of QOL score in those who had satisfactory sexual life and those with no change in the style of clothing. Similarly, those who had no change in dietary habits had higher scores in most of the components, except for sexual and body image scores. Of these, the difference noted due to change in style of clothing was statistically significant $(\mathrm{p}=0.013)$. Thus, the impact on the overall scores is not only due to the isolated improvement in the relevant sub-scores, but also due to improvement in other unrelated sub-scores (Table 5).

Those who claimed to be depressed soon after surgery had significantly lower scores in all components of QOL $(\mathrm{p}<0.05)$ (Table 6). Furthermore those who had suicidal thoughts at some point after stoma also had lower overall
QOL $(\mathrm{p}<0.05)($ Table 7). Significant reduction was seen in scores that measured social component which included, relationship with family, friends and making new relationships. Also the scores measuring concerns due to stoma, sleep, sexuality/body image were low. However, the difference noticed was not statistically significant.

The mean self-efficacy score was $70.57 \pm$ SD 14.68. About $50 \%$ had scores more than 75 . We noted significant correlation between self-efficacy in stoma care and QOL. There was significant positive association with overall score $(p=0.003)$ and components related to concerns of stoma $(p=0.002)$, sleep $(p=0.028)$, and social relationship $(\mathrm{p}=0.015)$ (Table 8$)$. There was a significant negative correlation between time taken to train to care for stoma and scores related to concerns of stoma. This means sooner they train themselves to care for the stoma 
Table 4 Association between QOL and ostomy related parameters

\begin{tabular}{|c|c|c|c|c|}
\hline & $\mathbf{N}$ & Mean & Standard deviation & $p$ value \\
\hline \multicolumn{5}{|c|}{ Overall QOL with type: ileostomy vs colostomy } \\
\hline lleostomy & 11 & 50.91 & 17.26 & \multirow[t]{2}{*}{0.519} \\
\hline Colostomy & 32 & 53.81 & 10.92 & \\
\hline \multicolumn{5}{|c|}{ Overall QOL with type loop vs end } \\
\hline Loop & 26 & 55.19 & 12.10 & \multirow[t]{2}{*}{0.178} \\
\hline End & 17 & 49.82 & 13.20 & \\
\hline \multicolumn{5}{|c|}{ Overall QOL with surgery type } \\
\hline Defunctioning ostomy & 19 & 54.17 & 10.54 & \multirow[t]{2}{*}{0.619} \\
\hline Other & 24 & 52.20 & 14.31 & \\
\hline \multicolumn{5}{|c|}{ Overall QOL with rectal surgery } \\
\hline Yes & 20 & 53.74 & 14.53 & \multirow[t]{2}{*}{0.749} \\
\hline No & 23 & 52.48 & 11.12 & \\
\hline \multicolumn{5}{|c|}{ Sexual/body image scores with rectal surgery } \\
\hline Yes & 20 & 2.65 & 0.8269 & \multirow[t]{2}{*}{0.689} \\
\hline No & 23 & 2.75 & 0.8540 & \\
\hline \multicolumn{5}{|c|}{ Overall QOL: permanent vs temporary } \\
\hline Permanent & 23 & 55.46 & 13.51 & \multirow[t]{2}{*}{0.188} \\
\hline Temporary & 20 & 50.32 & 11.35 & \\
\hline
\end{tabular}

better the QOL $(\mathrm{p}=0.003)$. There was no correlation between duration of follow up and both QOL and selfefficacy scores.

\section{Discussion}

The results of this study suggest that there is significant impact on the QOL following an ostomy. About $70 \%$ of the participants had overall scores less than $60 \%$. Our study is also compatible with other studies which showed similar problems faced by ostomy patients [7-9]. There were comparatively lower scores on components measuring stoma concerns and sleep in our cohort. The scores on sexuality/body image and social scores were comparatively better.

Only $16.3 \%$ had a comfortable income in our cohort and $32 \%$ did not have an income even to cover their basic needs. Sri Lanka being a developing country, this reflects the poor socioeconomic background the patients are from and this factor may have had an influence on reduced QOL. The overall QOL was not statistically different between the groups. However, the family relationship component had a statistically significant difference and those who had a comfortable income had a higher score. The additional economic burden due to the stoma may cause family problems and relationship issues which may have influenced the scores. These findings are also consistent with other studies which gave similar results
[10-12]. Therefore, it is important identify the individuals who are from a poor socioeconomic background and refer them to the social worker before surgery, to help them to find an alternative source of income and socioeconomic support, if they would become unable to continue their job following surgery. Furthermore, it is important to counsel those who will be able to continue their jobs following surgery, to avoid unemployment merely due to social concerns.

The majority of the participants who were sexually active before ostomy did not resume their sexual activity after surgery. Only $33.3 \%$ of participants resumed sexual activity. Therefore the findings are also consistent with other similar studies $[8,13]$. However, the proportion of patients resuming their sexual activity was considerably low in our population, and also the proportion of those who were satisfied with their sexual activity was also low. This may be due to lack of effective counselling of our patients. Furthermore the patients do not openly discuss these issues with the health care providers due to embarrassment. Therefore, it is essential to counsel the patients prior to surgery, especially those who would undergo rectal surgery, regarding the potential sexual issues and risk of impotence following rectal surgery. Furthermore, relevant patients should be routinely questioned about their sexual wellbeing during follow up assessments and prompt referral should be arranged as needed. 
Table 5 Association with QOL and problems due to ostomy

N Mean $\begin{aligned} & \text { Standard } \\ & \text { deviation }\end{aligned}$

Association with sexual satisfaction and QOL

Overall QOL score

$\begin{array}{lrlll}\text { Yes } & 8 & 54.56 & 16.02692 & 0.566 \\ \text { No } & 24 & 51.29 & 13.05682 & \\ \begin{array}{l}\text { Scores on concerns of stoma } \\ \quad\end{array} & & & & \\ \text { Yes } & 8 & 2.25 & 0.94281 & 0.853 \\ \quad \text { No } & 24 & 2.1875 & 0.77757 & \\ \begin{array}{l}\text { Scores on sleep } \\ \text { Yes }\end{array} & 8 & 2.5417 & 0.94176 & 0.783 \\ \text { No } & 24 & 2.4444 & 0.83212 & \end{array}$

Scores on family and social relationships

$\begin{array}{llll}\text { Yes } & 8 & 2.8571 & 1.00436\end{array}$

$\begin{array}{llll}\text { No } & 24 & 2.6607 & 0.96322\end{array}$

Scores on sexuality/body image

$\begin{array}{llll}\text { Yes } & 8 & 2.625 & 0.82496\end{array}$

$\begin{array}{llll}\text { No } & 24 & 2.5972 & 0.87906\end{array}$

Association with change in clothing style and QOL

Overall QOL score

No

$\begin{array}{lll}19 & 58.3884 & 11.92004\end{array}$

Yes

$24 \quad 48.8675 \quad 11.85794$

Scores on concerns of stoma

$$
\text { No }
$$

Yes

$19 \quad 2.4386 \quad 0.86818$

$\begin{array}{lll}24 & 2.0903 & 0.71893\end{array}$

Scores on sleep

$\begin{array}{llll}\text { No } & 19 & 2.8421 & 0.87749 \\ \text { Yes } & 24 & 23056 & 0.71503\end{array}$

Scores on family and social relationships

$\begin{array}{lllll}\text { No } & 19 & 3.1729 & 0.74775 & 0.005\end{array}$

$\begin{array}{llll}\text { Yes } & 24 & 2.3988 & 0.90741\end{array}$

Scores on sexuality/body image

$\begin{array}{llll}\text { No } & 19 & 2.9123 & 0.87378\end{array}$

$\begin{array}{llll}\text { Yes } & 24 & 2.5417 & 0.77903\end{array}$

Association with change in dietary habits and QOL

Overall QOL score

\begin{tabular}{lrrrr} 
No & 16 & 54.9544 & 15.16167 & 0.461 \\
Yes & 27 & 51.9604 & 11.11946 & \\
Scores on concerns of stoma & & & & \\
$\quad$ No & 16 & 2.4896 & 0.83326 & 0.122 \\
Yes & 27 & 2.0988 & 0.75427 & \\
Scores on sleep & & & & \\
No & 16 & 2.6667 & 1.03994 & 0.455 \\
Yes & 27 & 2.4691 & 0.681 & \\
Scores on family and social relationships & & \\
No & 16 & 2.75 & 0.98492 & 0.961 \\
Yes & 27 & 2.7354 & 0.89452 & \\
Scores on sexuality/body image & & & \\
No & 16 & 2.6042 & 1.00531 & 0.546 \\
Yes & 27 & 2.7654 & 0.72686 & \\
\hline \multicolumn{4}{l}{} \\
\end{tabular}

There was no significant difference between QOL and change in dietary habits which may indicate that they are able to successfully cope with the diet change. However, a study done in Netherlands in 2000 showed that there was significant reduction in the QOL in those who were prescribed dietary modifications [4]. Change in the style of clothing has caused a significant decrease in the QOL mainly due to the impact on the social component. Thus, change in the style of dressing may be a factor which limits their social interactions and in turn it affects the QOL. Furthermore, other researches also showed similar findings, although did not specifically mention a statistically significant difference in QOL among those who were affected by change in style of clothing $[9,14,15]$. Therefore special attention should be given when ostomy siting is done pre-operatively so that change in style of clothing is minimized.

About 46\% "felt depressed" soon after surgery which could be considered as a considerable proportion. The QOL was significantly low in those who "felt depressed" soon after surgery even after a median follow up duration of 38 months. Furthermore the QOL was significantly low in both overall score and scores on social relationships in those who had suicidal thoughts. Thus poor psychological well-being has a significant negative impact on the QOL especially on the social component. This finding is consistent with similar studies [16, 17]. This highlights the importance of psychological interventions in ostomy patients. The patients with depressive thoughts soon after surgery should be counselled appropriately and closely followed up to implement timely interventions.

There was a statistically significant positive correlation between self-efficacy in stoma care and the QOL similar to other studies $[18,19]$. However this should be interpreted cautiously as the score measures the perception of self-efficacy and not the actual self-efficacy. More than $50 \%$ of the participant scored above 75 which indicate high perception of self-efficacy. Furthermore there was a statistically significant negative association between time taken to learn to care for ostomy and QOL which implies sooner the learning in the initial period after surgery, the higher the long term QOL. This reflects the importance of education and training on stoma care in the initial period to improve QOL. Thus, education and training on ostomy care prior to surgery, and routine assessment of the skills of ostomy care during follow up visits by a specialised stoma therapist would be ideal.

We also acknowledge certain limitations in this study. As the study population is small and also they were treated at a single unit, the results cannot be generalized. Since it is a cross sectional analysis the causal inferences cannot be made in this study. 
Table 6 Association between QOL and feeling "depressed" soon after surgery

\begin{tabular}{|c|c|c|c|c|c|}
\hline & $\begin{array}{l}\text { Felt depressed soon } \\
\text { after surgery }\end{array}$ & $\mathrm{N}$ & Mean & Standard deviation & $\mathrm{p}$ value \\
\hline \multirow[t]{2}{*}{ Overall QOL score } & Yes & 19 & 46.7516 & 11.84774 & 0.001 \\
\hline & No & 22 & 59.2200 & 10.31910 & \\
\hline \multirow[t]{2}{*}{ Scores on concerns of stoma } & Yes & 19 & 1.9386 & 0.67862 & 0.015 \\
\hline & No & 22 & 2.5303 & 0.79787 & \\
\hline \multirow[t]{2}{*}{ Scores on sleep } & Yes & 19 & 2.2456 & 0.83031 & 0.015 \\
\hline & No & 22 & 2.8636 & 0.73217 & \\
\hline \multirow[t]{2}{*}{ Scores on family and social relationships } & Yes & 19 & 2.2857 & 0.83299 & 0.001 \\
\hline & No & 22 & 3.1753 & 0.78362 & \\
\hline \multirow[t]{2}{*}{ Scores on sexuality/body image } & Yes & 19 & 2.3333 & 0.80123 & 0.003 \\
\hline & No & 22 & 3.0606 & 0.68727 & \\
\hline
\end{tabular}

Table 7 Association between QOL and "thoughts of suicide/self-harm at some point due to ostomy"

\begin{tabular}{|c|c|c|c|c|c|}
\hline & $\begin{array}{l}\text { Thoughts of suicide/self-harm } \\
\text { at some point due to ostomy }\end{array}$ & $\mathrm{N}$ & Mean & Standard deviation & p value \\
\hline \multirow[t]{2}{*}{ Overall QOL score } & Yes & 5 & 42.2880 & 17.45353 & 0.042 \\
\hline & No & 38 & 54.4937 & 11.47986 & \\
\hline \multirow[t]{2}{*}{ Scores on concerns of stoma } & Yes & 5 & 2.0333 & 0.87718 & 0.536 \\
\hline & No & 38 & 2.2719 & 0.79546 & \\
\hline \multirow[t]{2}{*}{ Scores on sleep } & Yes & 5 & 2.0667 & 0.95452 & 0.173 \\
\hline & No & 38 & 2.6053 & 0.80111 & \\
\hline \multirow[t]{2}{*}{ Scores on family and social relationships } & Yes & 5 & 1.8571 & 0.88641 & 0.020 \\
\hline & No & 38 & 2.8571 & 0.86674 & \\
\hline \multirow[t]{2}{*}{ Scores on sexuality/body image } & Yes & 5 & 2.2000 & 1.09545 & 0.151 \\
\hline & No & 38 & 2.7719 & 0.78692 & \\
\hline
\end{tabular}

Table 8 Correlation between QOL and self-efficacy and time taken to learn to take care of stoma

\begin{tabular}{|c|c|c|c|c|}
\hline & Scores & $\mathbf{N}$ & Spearman's rho & $\mathrm{p}$ value \\
\hline \multirow[t]{5}{*}{ Self-efficacy } & Overall QOL & 43 & 0.446 & 0.003 \\
\hline & Concerns of stoma & 43 & 0.459 & 0.002 \\
\hline & Sleep & 43 & 0.336 & 0.028 \\
\hline & Family and other social relationships & 43 & 0.370 & 0.015 \\
\hline & Sexuality and body image & 43 & 0.214 & 0.167 \\
\hline \multirow[t]{5}{*}{ Time taken to learn to take care of stoma } & Overall QOL & 43 & -0.277 & 0.083 \\
\hline & Concerns of stoma & 43 & -0.462 & 0.003 \\
\hline & Sleep & 43 & -0.127 & 0.435 \\
\hline & Family and other social relationships & 43 & -0.095 & 0.558 \\
\hline & Sexuality and body image & 43 & -0.152 & 0.348 \\
\hline
\end{tabular}

\section{Conclusions}

To our knowledge this is the first study in Sri Lanka which assessed the QOL using validated instruments and analysed the possible contributory factors. Even though the study is limited by its small sample size, important observations were made in this study. The nature of problems faced by patients in developing countries in South Asia is different due to the difference in the cultural and ethnic background.

We noticed a significantly low QOL in ostomy patients. However we recommend large scale multicentre research to gain further insight and knowledge in the local setting. 
Furthermore areas like psychological well-being and sexual problems need to be studied as there is scarcity of insight in this aspect among Sri Lankan population. Health care providers should also address the multidimensional problems which include the psychosocial and sexual aspects in addition to the physical illness. Recruiting specialized stoma therapists and integrating with other non-surgical specialties may help to achieve this.

\section{Abbreviations}

QOL: quality of life; SQOL: stoma quality of life; SCSE: stoma care self-efficacy scale; BMI: body mass index.

\section{Authors' contributions}

UJ participated in study concept, study design, data collection and analysis, manuscript preparation. DNS contributed to study concept, manuscript preparation and final approval. All authors read and approved the final manuscript.

\section{Acknowledgements}

None.

This study was performed at the Professorial Surgical Unit, National Hospital of Sri Lanka.

\section{Competing interests}

The authors declare that they have no competing interests.

\section{Availability of data and materials}

As consent for publication was not obtained, data supporting above findings will not be made available in order to protect the participants'identity.

\section{Ethics approval and consent to participate}

The study protocol was submitted to and approved by the Ethics Committee of National of Sri Lanka and informed written consent was obtained before participating in the study.

Received: 4 February 2016 Accepted: 25 January 2017

Published online: 31 January 2017

\section{References}

1. Krouse RS, Grant M, Rawl SM, Mohler MJ, Baldwin CM, Coons SJ, McCorkle R, Schmidt CM, Ko CY. Coping and acceptance: the greatest challenge for veterans with intestinal stomas. J Psychosom Res. 2009;66(3):227-33.

2. de Paula MA. Performance of stoma therapy in the process of rehabilitation of ostomy patients. Revista brasileira de enfermagem 1996:49(1):17-22

3. Marquis P, Marrel A, Jambon B. Quality of life in patients with stomas: the Montreux Study. Ostomy Wound Manag. 2003;49(2):48-55.

4. Gooszen AW, Geelkerken RH, Hermans J, Lagaay MB, Gooszen HG. Quality of life with a temporary stoma: ileostomy vs. colostomy. Dis Colon Rectum. 2000;43(5):650-5.

5. Prieto $L$, Thorsen $H$, Juul K. Development and validation of a quality of life questionnaire for patients with colostomy or ileostomy. Health Qual Life Outcomes. 2005;3:62

6. Bekkers MJ, van Knippenberg FC, van den Borne HW, van BergeHenegouwen GP. Prospective evaluation of psychosocial adaptation to stoma surgery: the role of self-efficacy. Psychosom Med. 1996;58(2):183-91.
7. Golicki D, Styczen P, Szczepkowski M. Quality of life in stoma patients in Poland: multicentre cross-sectional study using WHOQOL-BREF questionnaire. Przeglad epidemiologiczny. 2013;67(3):491-6.

8. Anaraki F, Vafaie M, Behboo R, Maghsoodi N, Esmaeilpour S, Safaee A. Quality of life outcomes in patients living with stoma. Indian J Palliat Care. 2012;18(3):176-80.

9. Vonk-Klaassen SM, de Vocht HM, den Ouden ME, Eddes EH, Schuurmans MJ. Ostomy-related problems and their impact on quality of life of colorectal cancer ostomates: a systematic review. Quality Life Res. 2015;25:125-33.

10. Coons SJ, Chongpison Y, Wendel CS, Grant M, Krouse RS. Overall quality of life and difficulty paying for ostomy supplies in the Veterans Affairs ostomy health-related quality of life study: an exploratory analysis. Med Care. 2007;45(9):891-5.

11. Krouse RS, Herrinton LJ, Grant M, Wendel CS, Green SB, Mohler MJ, Baldwin CM, McMullen CK, Rawl SM, Matayoshi E, et al. Health-related quality of life among long-term rectal cancer survivors with an ostomy: manifestations by sex. J Clin Oncol. 2009:27(28):4664-70.

12. Pittman J, Rawl SM, Schmidt CM, Grant M, Ko CY, Wendel C, Krouse RS Demographic and clinical factors related to ostomy complications and quality of life in veterans with an ostomy. J Wound Ostomy Cont Nurs. 2008;35(5):493-503.

13. Reese JB, Finan PH, Haythornthwaite JA, Kadan M, Regan KR, Herman JM, Efron J, Diaz LA Jr, Azad NS. Gastrointestinal ostomies and sexual outcomes: a comparison of colorectal cancer patients by ostomy status. Support Care Cancer. 2014;22(2):461-8.

14. Neuman HB, Park J, Fuzesi S, Temple LK. Rectal cancer patients' quality of life with a temporary stoma: shifting perspectives. Dis Colon Rectum. 2012:55(11):1117-24

15. Neuman HB, Patil S, Fuzesi S, Wong WD, Weiser MR, Guillem JG, Paty PB, Nash GM, Temple LK. Impact of a temporary stoma on the quality of life of rectal cancer patients undergoing treatment. Ann Surg Oncol. 2011:18(5):1397-403.

16. Knowles SR, Wilson J, Wilkinson A, Connell W, Salzberg M, Castle D, Desmond P, Kamm MA. Psychological well-being and quality of life in Crohn's disease patients with an ostomy: a preliminary investigation. J Wound Ostomy Cont Nurs. 2013;40(6):623-9.

17. Ross L, Abild-Nielsen AG, Thomsen BL, Karlsen RV, Boesen EH, Johansen C. Quality of life of Danish colorectal cancer patients with and without a stoma. Support Care Cancer. 2007:15(5):505-13.

18. Wu HK, Chau JP, Twinn S. Self-efficacy and quality of life among stoma patients in Hong Kong. Cancer Nurs. 2007:30(3):186-93.

19. Wong SK, Young PY, Widder S, Khadaroo RG, Acute C. Emergency Surgery Group of the University of Alberta C: a descriptive survey study on the effect of age on quality of life following stoma surgery. Ostomy Wound Manag. 2013:59(12):16-23.

\section{Submit your next manuscript to BioMed Central} and we will help you at every step:

- We accept pre-submission inquiries

- Our selector tool helps you to find the most relevant journal

- We provide round the clock customer support

- Convenient online submission

- Thorough peer review

- Inclusion in PubMed and all major indexing services

- Maximum visibility for your research

Submit your manuscript at www.biomedcentral.com/submit
Ciomed Central 